ARTICLE

Received 29 Oct 2015 | Accepted 3 May 2016 | Published 10 Jun 2016

DOI: $10.1038 /$ ncomms11806

OPEN

\title{
Palladium/N-heterocyclic carbene catalysed regio and diastereoselective reaction of ketones with allyl reagents via inner-sphere mechanism
}

Da-Chang Bai ${ }^{1}$, Fei-Le Yu ${ }^{1}$, Wan-Ying Wang ${ }^{1}$, Di Chen ${ }^{1}$, Hao Li ${ }^{1}$, Qing-Rong Liu${ }^{1}$, Chang-Hua Ding ${ }^{1}$, Bo Chen ${ }^{2}$ \& Xue-Long Hou ${ }^{1,3}$

The palladium-catalysed allylic substitution reaction is one of the most important reactions in transition-metal catalysis and has been well-studied in the past decades. Most of the reactions proceed through an outer-sphere mechanism, affording linear products when monosubstituted allyl reagents are used. Here, we report an efficient Palladium-catalysed protocol for reactions of $\beta$-substituted ketones with monosubstituted allyl substrates, simply by using $\mathrm{N}$-heterocyclic carbene as ligand, leading to branched products with up to three contiguous stereocentres in a (syn, anti)-mode with excellent regio and diastereoselectivities. The scope of the protocol in organic synthesis has been examined preliminarily. Mechanistic studies by both experiments and density functional theory (DFT) calculations reveal that the reaction proceeds via an inner-sphere mechanism-nucleophilic attack of enolate oxygen on Palladium followed by $\mathrm{C}-\mathrm{C}$ bond-forming $\left[3,3^{\prime}\right]$-reductive elimination.

\footnotetext{
${ }^{1}$ State Key Laboratory of Organometallic Chemistry, Shanghai Institute of Organic Chemistry, Chinese Academy of Sciences, 345 Lingling Road, Shanghai 200032, China. ${ }^{2}$ Department of Chemistry and Chemical Biology, Baker Laboratory, Cornell University, Ithaca, New York 14853, USA. ${ }^{3}$ ShanghaiHong Kong Joint Laboratory in Chemical Synthesis, Shanghai Institute of Organic Chemistry, Chinese Academy of Sciences, 345 Lingling Road, Shanghai 200032, China. Correspondence and requests for materials should be addressed to B.C. (email: cberic@hotmail.com) or to X.-L.H. (email: xlhou@sioc.ac.cn).
} 
$\mathrm{T}$ he palladium-catalysed allylic substitution reaction of allyl reagents with nucleophiles has become one of the most important carbon-carbon and carbon-hetero-atom bond-forming processes ${ }^{1-4}$. In most cases, the reaction proceeds through an outer-sphere mechanism, in which the nucleophile attacks the allyl carbon of $\pi$-allyl-Pd complex, and affords linear products when monosubstituted allyl reagents are used ${ }^{1-12}$. Less commonly, the reaction can follow an inner-sphere mechanism; in this case, the nucleophilic attack is targeted at Pd, forming an intermediate at first, followed by reductive elimination ${ }^{13-20}$. Recently, several studies on Pd-catalysed allylic substitution/ coupling reactions via inner-sphere mechanism have been reported $^{21-33}$. The key $\mathrm{C}-\mathrm{C}$ bond-forming step was proposed to occur via $\left[3,3^{\prime}\right]$-reductive elimination in an allyl-Pd-allyl or allyl-Pd-nucleophile intermediate. For example, Stoltz ${ }^{27}$ achieved the construction of a chiral quaternary carbon centre at the $\alpha$-position of cyclic ketones using unsubstituted allyl carbonates in an intramolecular decarboxylative process (Fig. 1a) ${ }^{25-27}$. Morken realized excellent regio- and enantio-selectivities in the cross-coupling of monosubstituted allyl reagents with allyl boronates under Pd catalysis (Fig. $1 \mathrm{~b})^{28-32}$. These results reveal the unique character of the inner-sphere mechanism; in particular, branched products can be formed as major products when monosubstituted allyl reagents are used ${ }^{21,28}$. Pd-catalysed allylic substitution via an inner-sphere mechanism also found applications in organic synthesis ${ }^{26,32}$. However, so far only limited reaction modes following an inner-sphere process have been explored, that is, coupling of diallyl-Pd-species ${ }^{21,28-31}$ and an intramolecular decarboxylative process, with narrow

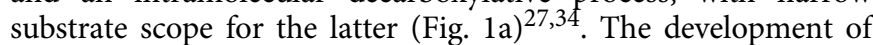
more reaction modes with wider substrate scope remains a great challenge.

Recently, we developed a regio- and chemo-tunable Pd-catalysed allylic alkylation with nitrogen nucleophiles, yielding branched allylated products with excellent regioselectivity; mechanistic investigations including DFT calculations support an inner-sphere mechanism for the reaction (Fig. 1c) ${ }^{33}$. In further investigations, we realized (with an oxygen nucleophile) Pd-catalysed allylic alkylation of monosubstituted allyl reagents by acyclic ketones. Acyclic compounds having up to three

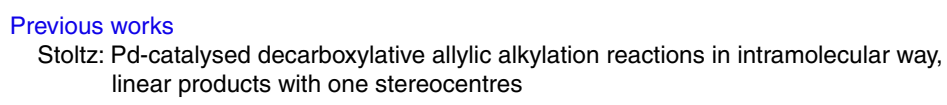

a

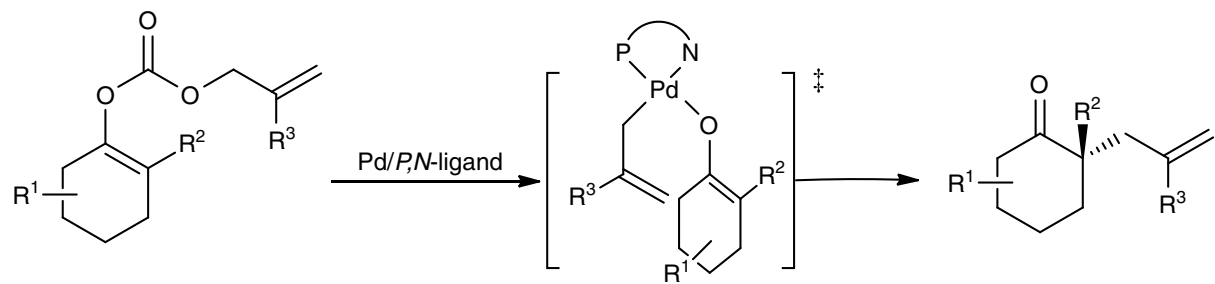

Morken: Pd-catalysed allyl-allyl cross-coupling branched products with two stereocentres

b

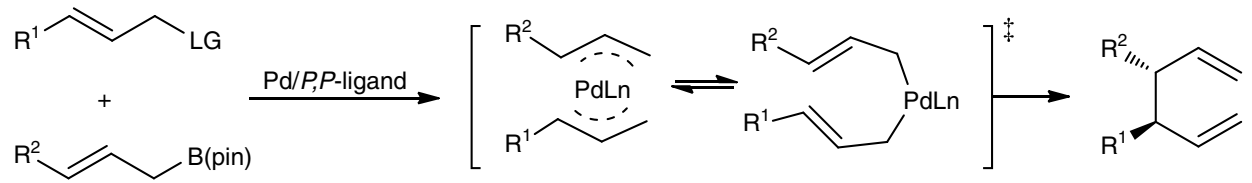

Hou: $\mathrm{PPh}_{3}$ as ligand with Nitrogen nucleophile branched products with two stereocentres

C

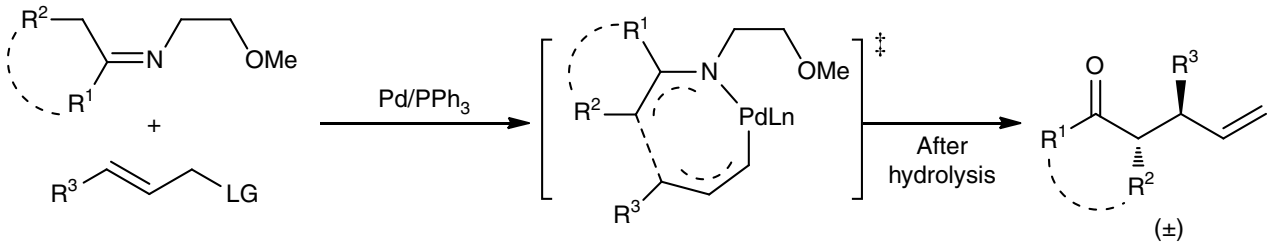

This work:

$\mathrm{NHC}$ as ligand with Oxygen nucleophile

branched products with three contiguous stereocentres

d<smiles>[R]C([R])CC(=O)c1ccccc1</smiles>

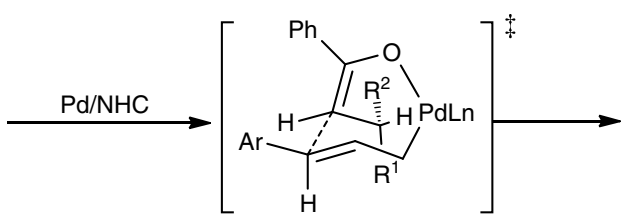

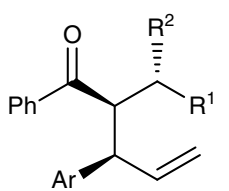

$( \pm)$

Figure 1 | Examples of Pd-catalysed allylic alkylation following an inner-sphere mechanism. (a) Pd-Catalysed intramolecular decarboxylative allylic alkylation. (b) Pd-catalysed allyl-allyl cross-coupling reaction, branched products with two stereocentres were given. (c) Pd-catalysed allylic alkylation with nitrogen as nucleophile affording branched products with two stereocentres. (d) Pd-catalysed allylic alkylation with oxygen as nucleophile affording branched products with three contiguous stereocentres. 
contiguous stereocentres can be obtained with excellent regio and diastereoselectivities (Fig. 1d). The key to high selectivity is the use of an $\mathrm{N}$-heterocyclic carbene (NHC) as ligand. In this paper, we would like to report this new type of $\mathrm{Pd} / \mathrm{NHC}$-catalysed allylic alkylation (Fig. 1d) as well as mechanistic studies on the reaction by both experiments and DFT calculations. The scope of the protocol in organic synthesis is also examined preliminarily.

\section{Results}

Reaction design. To test whether oxygen nucleophiles are also compatible, as nitrogen nucleophiles are, in the $\mathrm{Pd} / \mathrm{PPh}_{3}$ catalysed allylic substitution to give branched products via an inner-sphere mechanism ${ }^{33}$, we began our investigations with the reaction of propiophenone la with cinnamyl tert-butyl carbonate 2a, using $\left[\mathrm{Pd}\left(\eta^{3}-\mathrm{C}_{3} \mathrm{H}_{5}\right) \mathrm{Cl}\right]_{2}$ and $\mathrm{PPh}_{3}$ as catalyst and $t$-BuOK or lithium diisopropylamide as base. Unfortunately, the linear product was obtained as the major component in both cases, with branched to linear ratios $(\mathrm{B} / \mathrm{L})$ of $6 / 94$ and $15 / 85$, respectively, despite high yields (95\% and 98\%). Considering the similar coordination chemistry of NHC and phosphine ligands but different stereochemistry of reactions using the two types of ligands ${ }^{35}$, we envisioned that using NHC ligand, instead of $\mathrm{PPh}_{3}$, in the current reaction might lead to predominantly branched product. Indeed, with imidazolium salts $\mathrm{IPr} \cdot \mathrm{HCl}(\mathbf{L 1})$, the precursor to corresponding NHC ligand on deprotonation, branched product 3a was generated in $95 \%$ yield with a B/L ratio of $96 / 4$ in the reaction of 1 a with 2 a (entry 1, Table 1). Since NHC has a better performance than $\mathrm{PPh}_{3}$, leading to highly selective formation of branched product in the reaction, only NHC ligands were used in the subsequent reaction condition screening.
The diastereomeric ratio $(d r)$ for the reaction of $\mathbf{1 a}$ and $\mathbf{2 a}$ in the presence of an NHC ligand, determined by the ratio of syn-3/anti-3, was modest, 20/80 (entry 1, Table 1). To increase the diastereoselectivity of this reaction, ketones of substituted 1a were tested. Reaction of butyrophenone $\mathbf{1 b}$ did not show any increase in diastereoselectivity (entry 2, Table 1). Surprisingly, when $\beta$-methyl butyrophenone 1c was use as the substrate, the diastereoselectivity was reversed, and the $s y n$-isomer became the major product with a syn/anti ratio of 85/15 (entry 3 versus entry 1 , Table 1 ).

Next, we examined the effect of the structure of the NHC ligand on the diastereoselectivity of this reaction. Using an NHC ligand with a less sterically bulky aryl substituent, derived from L2, or 1,3-di-tert-butyl NHC, derived from L3, led to predominant linear product in low yield (entries 4 and 5, Table 1). A lower yield was obtained if the reaction was run at lower temperature (entry 6 versus entry 3, Table 1). Using an $\mathrm{NHC}$ ligand derived from $\mathrm{S}-\mathrm{IPr} \cdot \mathrm{HCl}(\mathbf{L 4})$, a dihydrogenated form of $\mathrm{IPr} \cdot \mathrm{HCl}$ (L1), high yields with excellent regio and diastereoselectivities were achieved (entry 7, Table 1; see Supplementary Table 5 for details). These results show that the structure of the NHC ligand is critical in controlling the regio and diastereoselectivities of the reaction.

In addition to ketones, some other carbonyl compounds were also examined in our catalyst system. Reaction of butyryl trimethylsilane $\mathbf{1 b a}$ led to $\mathbf{3 b a}$ in $72 \%$ yield with excellent regio and diastereoselectivities (entry 8 , Table 1 ). Similar yield and $\mathrm{B} / \mathrm{L}$ ratio, yet much lower dr were observed in the reaction of $\beta$-methyl substituted butyryl trimethylsilane 1ca (entry 9, Table 1). No desired product was observed when $\mathrm{N}$-acyl pyrrole 1bb (entry 10, Table 1) or ethyl acetate (not shown in the table) was used as substrate.

Table 1 | Influences of reaction parametes on Pd-catalysed reaction of ketone 1a-c with allyl substrate $2 a^{\star}$.
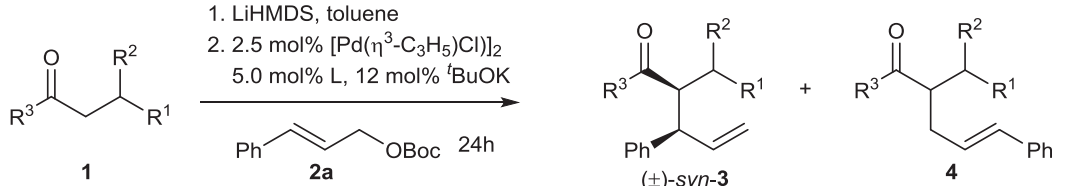

1a: $R^{1}=H ; R^{2}=H ; R^{3}=P h ; \quad$ ba: $R^{1}=H ; R^{2}=M e ; R^{3}=T M S$

1b: $R^{1}=H ; R^{2}=M e ; R^{3}=P h ; \quad$ 1ca: $R^{1}=M e ; R^{2}=M e ; R^{3}=T M S ;$

1c: $R^{1}=M e ; R^{2}=M e ; R^{3}=P h ; \quad$ 1bb: $R^{1}=H ; R^{2}=M e ;$<smiles>[R11]Cn1cccc1</smiles>

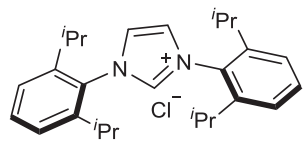

L1: IPr•HCI

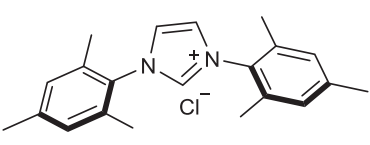

L2

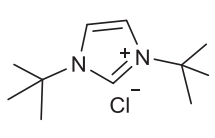

13

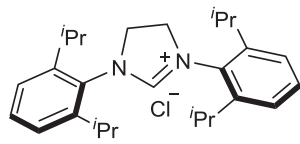

L4: S-IPr•HCI

\begin{tabular}{|c|c|c|c|c|c|c|}
\hline Entries & 1 & $\mathbf{L}$ & $\mathrm{T}\left({ }^{\circ} \mathrm{C}\right)$ & $3 / 4^{\dagger}$ & $d r^{\dagger}$ & Yield (\%) \\
\hline 1 & $1 \mathbf{a}$ & L1 & 50 & $96 / 4$ & $20 / 80$ & 95 (3a) \\
\hline 2 & 16 & $\mathbf{L 1}$ & 50 & $95 / 5$ & $30 / 70$ & $98(\mathbf{3 b})$ \\
\hline 3 & 1c & $\mathbf{L 1}$ & 50 & $95 / 5$ & $85 / 15$ & $83(\mathbf{3 c})$ \\
\hline 4 & 1c & $\mathbf{L 2}$ & 50 & $15 / 85$ & - & $32(\mathbf{3 c})$ \\
\hline 5 & 1c & L3 & 50 & $<5 / 95$ & - & $33(\mathbf{4 c})$ \\
\hline 6 & 1c & $\mathbf{L 1}$ & RT & $92 / 8$ & $92 / 8$ & $50(\mathbf{3 c})$ \\
\hline 7 & 1c & L4 & RT & $99 / 1$ & $92 / 8$ & $98(3 \mathbf{c})$ \\
\hline 8 & $1 \mathrm{ba}$ & L4 & 30 & $91 / 9$ & 7/93 & 72 (3ba) \\
\hline $9^{\S}$ & 1ca & L4 & 30 & $91 / 9$ & $70 / 30$ & 70 (3ca) \\
\hline 10 & $1 \mathrm{bb}$ & L4 & 30 & - & - & NR \\
\hline
\end{tabular}

$N R$, no reaction; $R T$, room temperature; $T$, temperature.

${ }^{\star}$ Reaction conditions: $\mathbf{1} / \mathrm{LiHMDS} / \mathbf{2 a} \mathbf{a}\left[\mathrm{Pd}\left(\eta^{3}-\mathrm{C}_{3} \mathrm{H}_{5}\right) \mathrm{Cl}\right]_{2} /$ ligand $=200 / 200 / 100 / 2.5 / 5 ; 0.1 \mathrm{M}$ of ketone $\mathbf{1}$

$\dagger$ Determined by ${ }^{1} \mathrm{H}$ NMR, $d r$ is the ratio of syn-3/anti-3.

$\ddagger$ Isolated yield.

\$The configuration for major component of $\mathbf{3} \mathbf{c a}$ is not determined. 
We also investigated preliminarily the enantioselectivity of reactions of $\mathbf{1 b}$ and 1c using chiral NHCs. So far, only poor enantioselectivity with lower regio and diastereoselectivities has been achieved (see Supplementary Tables 7 and 8 for details). Realizing highly asymmetric induction in this type of reaction is the task of further investigations.

Using $\beta$-substituted ketones to construct three stereocentres. The structural motif of three contiguous stereocentres in an acyclic system can be found in a wide range of natural products, pharmaceuticals and synthetic building blocks ${ }^{36-38}$. In view of above results and following investigations on the mechanism (vide infra, Mechanistic investigations), we reasoned that highly selective formation of three contiguous stereocentres in this reaction might be possible if we introduce a chiral centre at the $\beta$ position of $1 \mathrm{c}$ by changing one methyl at the $\beta$ position to other groups. Following this thought, reactions of ketones 1 with different $\beta$-substituents were carried out. While using ketones 1d and 1e with, respectively, ${ }^{n}$ hexyl and ethyl at the $\beta$ position led to very low diastereoselectivities (entries 1 and 2, Table 2), using $\beta$-phenyl substituted ketone 1f results in $98 \%$ branched product (syn, anti)-3f with 86/14 $d r$ (entry 3, Table 2; see Supplementary Table 6 for details). These results seemed to indicate that unsaturated groups at the $\beta$ position are necessary to achieve high $d r$, presumably due to some favourable interaction between the unsaturated group at the $\beta$ position of ketone and the phenyl on allyl $l^{39-41}$. It could be deduced that high stereoselectivity might also be obtained if other unsaturated groups were installed at the $\beta$ position of ketone. Indeed, higher stereoselectivity was observed in reactions of $\beta$-alkenyl ketone $\mathbf{1 g}$ (ref. 42) and $\mathbf{1 h}$, and $\beta$-alkynyl ketone $1 \mathbf{i}$ (ref. 43), with $d r$ of 77/23, 86/14 and 93/7, respectively (entries 4-6 versus entry 1, Table 2). Note, also the high yields and regioselectivity for $\mathbf{3 g}(92 \%, \mathrm{~B} / \mathrm{L}=93 / 7)$ and $\mathbf{3 i}$ $(99 \%, B / L=95 / 5)$, and somewhat lower yield and regioselectivity of reaction of $Z$-type $\beta$-alkenyl ketone $\mathbf{1 h}$, compared with those of reaction of $E$-type $\beta$-alkenyl ketone $\mathbf{1 g}$.

Substrate scope. With the optimized reaction conditions, the compatibility of both ketone substrates and allyl reagents in the reaction was studied. As depicted in Table 3, the reaction is efficient for a wide range of $\beta$-substituted ketones, 1f-11, affording the branched products $\mathbf{3 f}-\mathbf{3 l}$ bearing three contiguous stereocentres in nearly quantitative yields, with excellent regio and diastereoselectivities. Specifically, not only $\beta$-phenyl ketones (1f and $\mathbf{1 j}$ ), but also $\beta$-alkynyl ketones with a variety of terminal substituents on alkynyl (1i, $\mathbf{1 k}$ and $\mathbf{1 1})$ are suitable substrates for this reaction. Notably, ketones with sterically bulky substituents also react smoothly to produce the corresponding allylated product $3 y$ in high yield with high diastereoselectivity, despite the somewhat lower $\mathrm{B} / \mathrm{L}$ ratio of $85 / 15$. Regarding the allyl reagents, we first examined mono-aryl substituted allyl reagents with both electron-withdrawing and donating substituents. With $\beta$-triisopropylsilylacetylenyl ketone $\mathbf{1 1}$ as nucleophile, allylated product 31-3v were obtained in excellent yields ( $>90 \%$ ) with excellent regio and diastereoselectivities $(B / L>90 / 10$ and $d r>93 / 7)$. Using $\beta$-methyl butyrophenone 1c as nucleophile, equally good yields and selectivities were obtained for $\mathbf{3 c a}-\mathbf{3 c e}$. We also found that furanyl- and naphthyl-substituted allyl reagents are compatible in the reaction, delivering $3 \mathbf{w}$ and $\mathbf{3 x}$. Note that the structures of one enantiomer of each of $( \pm)-s y n-3 c$ and $( \pm)-(s y n$, anti)-3f have been determined by X-ray crystallography and are shown in Table 3.

Applications. To demonstrate the usefulness of this protocol, gram-scale reactions were carried out. Under optimal conditions, reaction of 1,6-enyne $\mathbf{1 i}$ can be scaled up, affording $1.34 \mathrm{~g}$ of product 3i, with almost no decrease in yield and selectivities (Fig. 2a). Our protocol can be used to allylate the C16 position of estrone 3-methyl ether 6, providing product 7 in $96 \%$ yield with 84/16 B/L and 91/9 $d r$ (Fig. 2b). Since optically active $\beta$-substituted ketones are easily available ${ }^{44-49}$, the capacity of this reaction for chirality transfer from optically active substrates was explored (Fig. 2cd). Products (3R, $4 S, 5 S)-3 \mathbf{j}$ and $(3 R, 4 S, 5 S)-\mathbf{3 1}$ were obtained in excellent yields with excellent regio and diastereoselectivities without loss of optical activity when optical active ketones $(S)$-1j (ref. 47) and (S)-11 (ref. 48) were used.

1,6-Enynes are important and versatile synthetic intermediates ${ }^{50,51}$. Thus, further transformations of the 1,6-enyne product $3 \mathbf{i}$, generated by the titled $\mathrm{Pd} / \mathrm{NHC}$-catalysed allylic substitution, were studied. Subjecting $\mathbf{3 i}$ to Pauson-Khand reaction conditions leads to bicyclo[3.3.0]octane $\mathbf{8}$, which

Table 2 | Reaction of ketone 1d-I with allyl substrate $2 a^{\star}$.

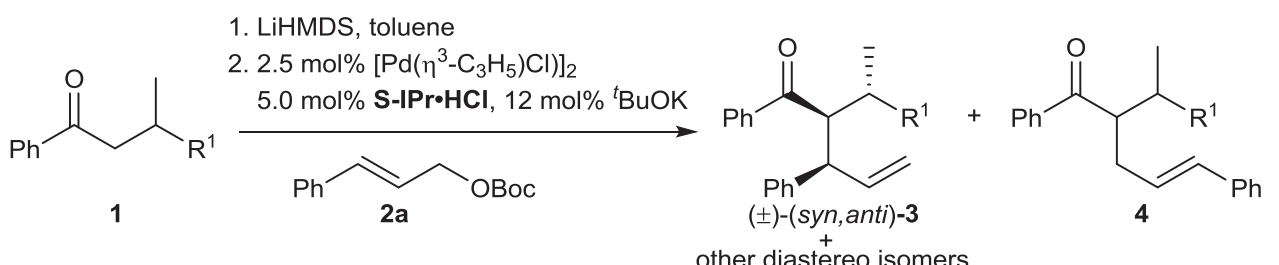

d: $\mathrm{R}^{1}=\left(\mathrm{CH}_{2}\right)_{5} \mathrm{CH}_{3} ; \mathbf{e}: \mathrm{R}^{1}=\mathrm{Et} ; \mathbf{f}: \mathrm{R}^{1}=\mathrm{Ph} ; \mathbf{g}: \mathrm{R}^{1}=(E)-\mathrm{CH}=\mathrm{C}\left(\mathrm{CH}_{2}\right)_{4} \mathrm{CH}_{3} ;$

h: $\mathrm{R}^{1}=(\mathrm{Z})-\mathrm{CH}=\mathrm{C}\left(\mathrm{CH}_{2}\right)_{3} \mathrm{CH}_{3} ; \mathbf{i}: \mathrm{R}^{1}=\overline{\overline{ }}\left(\mathrm{CH}_{2}\right)_{3} \mathrm{CH}_{3}$

\begin{tabular}{lllll}
\hline Entries & $\mathbf{1}$ & $\mathbf{3 / 4}^{\dagger}$ & $\boldsymbol{d r}^{\dagger}$ & Yield (\%) $^{\ddagger}$ \\
\hline 1 & $\mathbf{1 d}$ & $95 / 5$ & $57 / 43$ & $56(\mathbf{3 d})$ \\
2 & $\mathbf{1 e}$ & $98 / 2$ & $60 / 40$ & $98(\mathbf{3 e})$ \\
3 & $\mathbf{1 f}$ & $95 / 5$ & $86 / 14$ & $98(\mathbf{3 f})$ \\
4 & $\mathbf{1 g}$ & $93 / 7$ & $77 / 23$ & $92(\mathbf{3 g})$ \\
5 & $\mathbf{1 h}$ & $88 / 12$ & $86 / 14$ & $56(\mathbf{3 h})$ \\
6 & $\mathbf{1 i}$ & $95 / 5$ & $93 / 7$ & $99(\mathbf{3 i})$
\end{tabular}

${ }^{*}$ Reaction conditions: $\mathbf{1} / \mathrm{LiHMDS} / \mathbf{2 a} /\left[\mathrm{Pd}\left(\eta^{3}-\mathrm{C}_{3} \mathrm{H}_{5}\right) \mathrm{Cl}\right]_{2} / \mathrm{S}-\mathrm{IPr} \cdot \mathrm{HCl}=200 / 200 / 100 / 2.5 / 5 ; 0.1 \mathrm{M}$ of ketone $\mathbf{1} ; 30^{\circ} \mathrm{C}, 24 \mathrm{~h}$.

$\dagger$ Determined by ${ }^{1} \mathrm{H}$ NMR, $d r$ is the ratio of $( \pm)$-(syn,anti)-3/other diastereo isomers.

$\ddagger$ łsolated yield. 


\section{Table 3 | Substrate scope of the reaction^.}

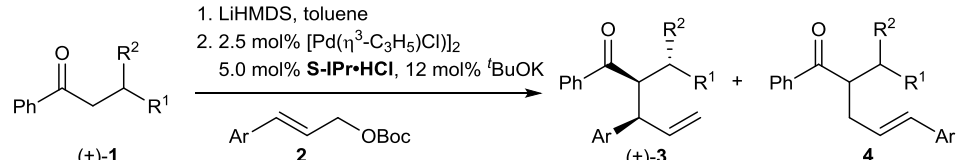

$( \pm)-1$

$( \pm)-3$

$\mathrm{j}: \mathrm{R}^{1}=\mathrm{Ph}, \mathrm{R}^{2}=\mathrm{Et} ; \mathbf{k}: \mathrm{R}^{1}=\overline{\overline{ }} \mathrm{Ph}, \mathrm{R}^{2}=\mathrm{Me}$;

I: $\mathrm{R}^{1}=\bar{\equiv} \mathrm{Si}\left({ }^{\mathrm{i}} \mathrm{Pr}\right)_{3}, \mathrm{R}^{2}=\mathrm{Me} ; \mathbf{m}: \mathrm{R}^{1}=\overline{\overline{ }} \mathrm{Si}\left({ }^{i} \mathrm{Pr}\right)_{3}, \mathrm{R}^{2}={ }^{\mathrm{i}} \mathrm{Pr}$
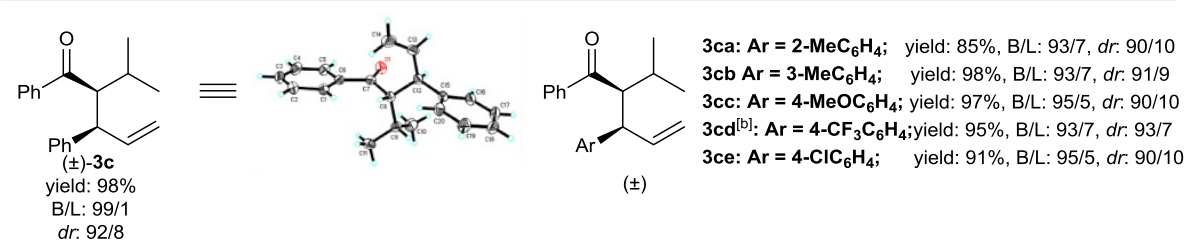

$( \pm)$
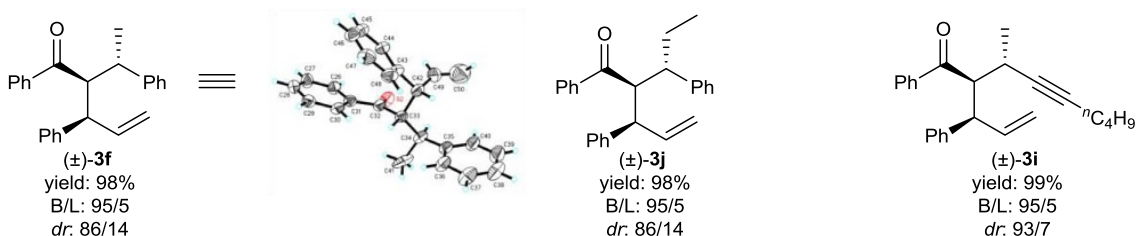<smiles>C=CC(c1ccccc1)[C@H](C(=O)c1ccccc1)[C@@H](C)C#Cc1ccccc1</smiles><smiles>C=C[C@H](c1ccccc1)[C@H](C(=O)c1ccccc1)[C@@H](C)C#C[SeH2+]</smiles><smiles>C=C[C@H](c1ccc(C)cc1)[C@@H](C(=O)c1ccccc1)[C@@H](C)C#C[GeH-]C(C)C</smiles><smiles></smiles>

$( \pm)-3 \mathbf{k}$

yield: $98 \%$

B/L: $90 / 10$

$$
\begin{gathered}
( \pm)-\mathbf{3 I}^{\ddagger} \\
\text { yield: } 99 \% \\
\text { B/L: } 97 / 3 \\
\text { dr. } 96 / 4
\end{gathered}
$$

$( \pm)-3 m^{\dagger}$
yield: $99 \%$

B/L: $97 / 3$

dr. $96 / 4$

$( \pm)-3 n^{\S}$

yield: $98 \%$

B/L: $94 / 6$

dr. $95 / 5$

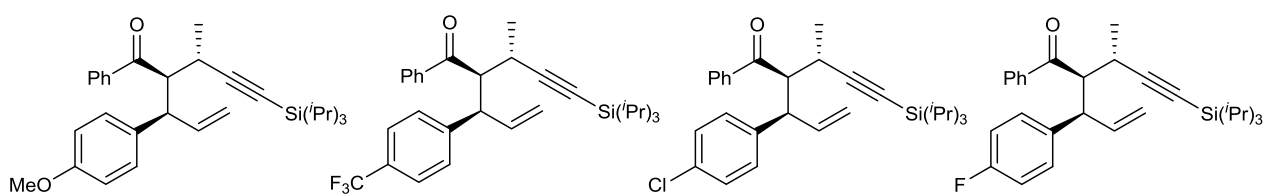

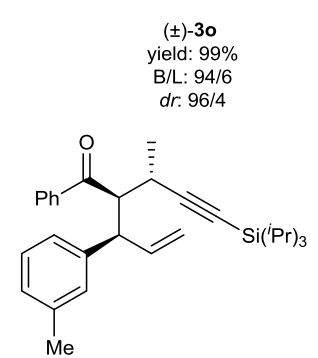<smiles>C=C[C@H](c1cccc(OC)c1)[C@@H](C(=O)c1ccccc1)[C@@H](C)C#C[GeH3]</smiles>

$$
\begin{gathered}
( \pm)-3 q \\
\text { yield: } 98 \% \\
\text { B/L: } 92 / 8 \\
d r .95 / 5
\end{gathered}
$$

( \pm ) $-3 \mathbf{r}$

yield: $94 \%$

B/L: $94 / 6$<smiles></smiles><smiles>C=C[C@H](c1ccccc1Cl)[C@H](C(=O)c1ccccc1)[C@@H](C)C#C[AsH3]</smiles>

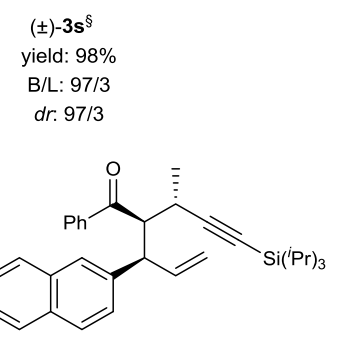

$$
\begin{gathered}
\left(^{ \pm}\right)-3 t^{\S} \\
\text { yield: } 95 \% \\
\text { B/L: } 94 / 6 \\
d r .95 / 5
\end{gathered}
$$

$$
\begin{gathered}
( \pm)-3 \mathbf{u}^{\S} \\
\text { yield: } 96 \% \\
\text { B/L: } 90 / 10 \\
d r: 93 / 7
\end{gathered}
$$

yield: $99 \%$

dr. $98 / 2$

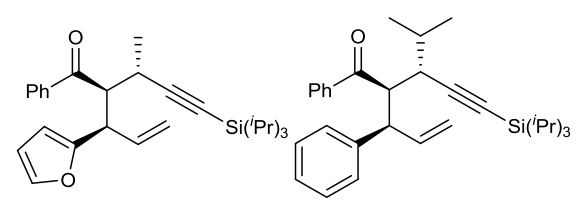

$$
\begin{gathered}
( \pm)-3 w^{\|} \\
\text {yield: } 90 \% \\
\text { B/L: } 95 / 5 \\
\text { dr: } 98 / 2
\end{gathered}
$$

$$
\begin{gathered}
\text { ( } \pm \text { )-3x } \\
\text { yield: } 98 \% \\
\text { B/L: } 95 / 5 \\
d r .95 / 5
\end{gathered}
$$

$$
\begin{gathered}
( \pm)-3 y \\
\text { yield: } 98 \% \\
\text { B/L: } 85 / 15 \\
d r: 93 / 7
\end{gathered}
$$

${ }^{*}$ Reaction conditions:1/LiHMDS $/ \mathbf{2} /\left[\mathrm{Pd}\left(\eta^{3}-\mathrm{C}_{3} \mathrm{H}_{5}\right) \mathrm{Cl}\right]_{2} / \mathrm{S}-\mathrm{IPr} \cdot \mathrm{HCl}=200 / 200 / 100 / 2.5 / 5 ; 0.1 \mathrm{M}$ of ketone $\mathbf{1} ; \mathrm{T}=30^{\circ} \mathrm{C} ; \mathrm{B} / \mathrm{L}$ and $d r$ was determined by ${ }^{1} \mathrm{H} \mathrm{NMR}, \mathrm{dr}$ is the ratio of $( \pm$ )-(syn,anti)-3/other diastereoisomers; Isolated yield. $\dagger \mathrm{T}=50^{\circ} \mathrm{C}$. $\ddagger$ Solvent $=\mathrm{THF}$. $§ \mathrm{OB}$ oc of $\mathbf{2}$ was replaced with OP(OEt)$)_{2}$. IIThe yield was determined by ${ }^{1} \mathrm{H}$ NMR. 
a<smiles>CCCC#CC(C)CC(=O)c1ccccc1</smiles>

1. LiHMDS, toluene

2. $2.5 \mathrm{~mol} \%\left(\mathrm{Pd}\left(\eta^{3}-\mathrm{C}_{3} \mathrm{H}_{5}\right) \mathrm{Cl}\right)_{2}$

$5.0 \mathrm{~mol} \% \mathrm{~S}-\mathrm{IPr} \cdot \mathrm{HCl}, 12 \mathrm{~mol} \%{ }^{t} \mathrm{BuOK}$

$\curvearrowright \mathrm{OBoc} 30^{\circ} \mathrm{C}$

2a $0.94 \mathrm{~g}$<smiles>C=C[C@H](c1ccccc1)[C@@H](C(=O)c1ccccc1)[C@@H](C)C#CCOCC</smiles>

97\% yield, 95/5 B/L, 95/5 dr<smiles>COc1ccc2c(c1)CC[C@@H]1[C@@H]2CC[C@]2(C)C(=O)CC[C@@H]12</smiles>

6<smiles>CC[C@H](CC(=O)c1ccccc1)c1ccccc1</smiles>

(S)-1j

2.0 equiv

$96 \%$ ee

d

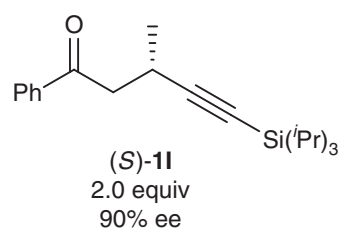

1. LiHMDS, toluene

2. $2.5 \mathrm{~mol} \%\left(\mathrm{Pd}\left(\eta^{3}-\mathrm{C}_{3} \mathrm{H}_{5}\right) \mathrm{Cl}\right)_{2}$ $5.0 \mathrm{~mol} \% \mathrm{~S}-\mathrm{IPr} \bullet \mathrm{HCl}, 12 \mathrm{~mol} \%{ }^{t} \mathrm{BuOK}$

$\longrightarrow$ OBoc $30^{\circ} \mathrm{C}$

$2 a$

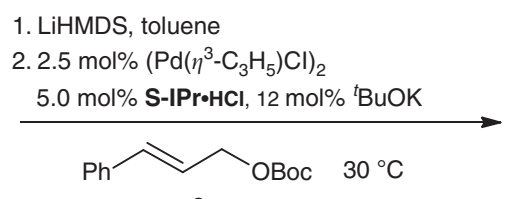

$2 a$

1.0 equiv

1. LiHMDS, toluene

2. $2.5 \mathrm{~mol} \%\left(\mathrm{Pd}\left(\eta^{3}-\mathrm{C}_{3} \mathrm{H}_{5}\right) \mathrm{Cl}\right)_{2}$ $5.0 \mathrm{~mol} \% \mathrm{~S}-\mathrm{IPr} \bullet \mathrm{HCl}, 12 \mathrm{~mol} \%{ }^{t} \mathrm{BuOK}$

$\curvearrowright \mathrm{OBoc} 30^{\circ} \mathrm{C}$

2a

1.0 equiv<smiles>C=C[C@H](c1ccccc1)[C@H]1C[C@H]2CCc3cc(OC)ccc3[C@H]2[C@@H]2CC[C@]1(C)C2=O</smiles>

7: $96 \%$ yield, 84/16 B/L, 91/9 dr<smiles>C=C[C@H](c1ccccc1)[C@H](C(=O)c1ccccc1)[C@H](CC)c1ccccc1</smiles>

(3R, 4S, 5S)-3j $>98 / 2 \mathrm{~B} / \mathrm{L}, 86 / 14 d r$ $96 \%$ ee, $98 \%$ yield

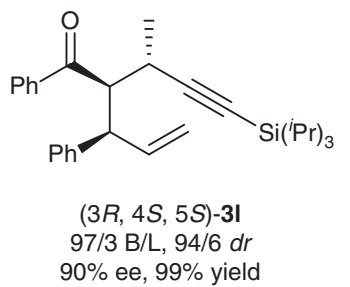

Figure 2 | Applications of the titled reaction. (a) Reaction on a gram-scale. (b) Allylation of estrone 3-methyl ether at the C16 position. (c) and (d) Reactions with chirality transfer from optically active substrates without loss of optical activity.

a<smiles>C=C[C@H](c1ccccc1)[C@H](C(=O)c1ccccc1)[C@@H](C)C#CCCC</smiles>

( \pm -3i

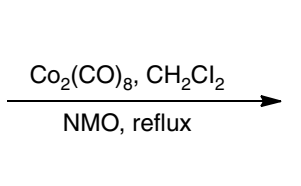

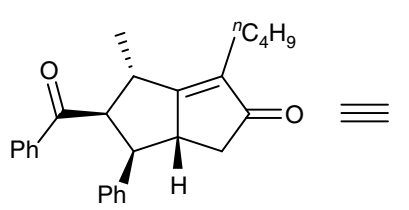

( \pm )-8

$70 \%$ yield

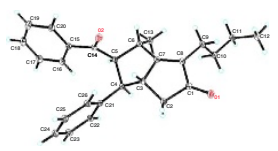

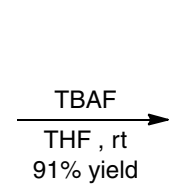

$91 \%$ yield

(3R, 4S, 5S)-3I

$90 \%$ ee<smiles>C#C[C@H](C)[C@H](C(=O)c1ccccc1)[C@H](C=C)c1ccccc1</smiles>

$90 \%$ ee

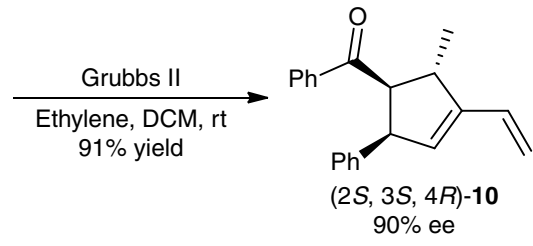

Figure 3 | Transformation of reaction products. (a) Pauson-Khand reaction with $\mathbf{3 i}$. (b) Cyclization reaction of $\mathbf{3}$ without loss of optical activity.

has been found to be a core skeleton in many natural products $^{52,53}$, in $70 \%$ yield with excellent stereoselectivity (Fig. 3a). Also, desilylation of $3 \mathbf{i}$ with tetra- $n$-butylammonium fluoride, followed by intramolecular cyclization in the presence of ethylene and Grubbs II catalyst, yields tetra-substituted cyclopentene $(2 S, 3 S, 4 R)-\mathbf{1 0}$ with three contiguous chiral centres in $83 \%$ yield without loss of optical activity (Fig. 3b).
The 1-vinyl cyclopentene framework in $\mathbf{1 0}$ is a useful building block in the synthesis of many complex molecules ${ }^{54-57}$.

Mechanistic investigations. To shed some light on the reaction mechanism, deuterium-labelled and cyclic allyl reagents were used as probes. According to the known stereochemistry 


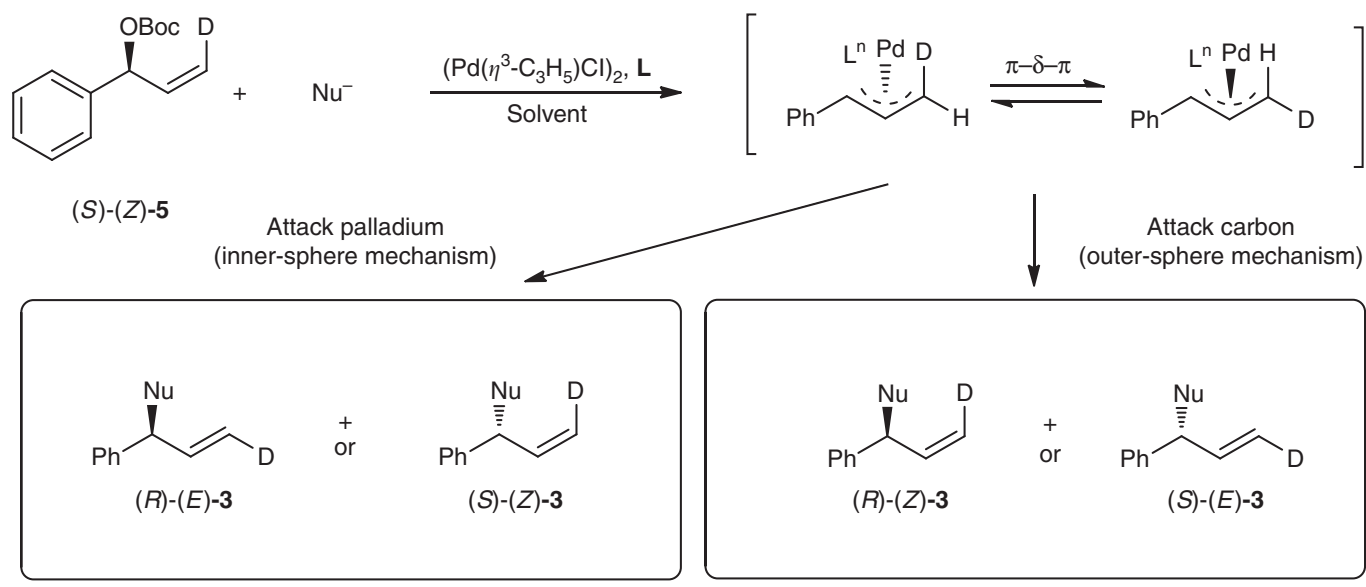

Figure 4 | Stereochemistry of Pd-catalysed reaction of nucleophile with (S)-(Z)-5 via outer- and inner-sphere attack mechanisms. $(R)-(E)-3$ and/or $(S)-(Z)-\mathbf{3}$ will be obtained by nucleophile attacks on palladium via an inner-sphere mechanism, whereas $(R)-(E)-\mathbf{3}$ and/or $(S)$-(Z)-3 will be afforded if the nucleophile attacks on carbon via an outer-sphere mechanism.

a<smiles>CCC(=O)c1ccccc1</smiles>

1a

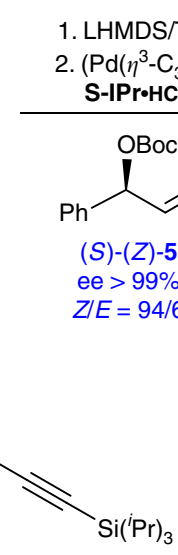

$(S)-1 \mathrm{~h}$ $90 \%$ ee

b<smiles>C[C@@H](C#C[GeH2])CC(=O)c1ccccc1</smiles>

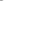

C<smiles>CC(C)CC(=O)c1ccccc1</smiles>

$1 c$
1. LiHMDS, THF

2. $2.5 \mathrm{~mol} \%\left(\mathrm{Pd}\left(\eta^{3}-\mathrm{C}_{3} \mathrm{H}_{5}\right) \mathrm{Cl}\right)_{2}$ $5.0 \mathrm{~mol} \% \mathrm{~S}-\mathrm{IPr} \cdot \mathrm{HCl}, 12 \mathrm{~mol} \%{ }^{\mathrm{t}} \mathrm{BuOK}$<smiles>[2H]/C=C\[C@@H](O[Na])c1ccccc1</smiles>

$(S)-(Z)-5$

ee $>99 \%, Z / E=94 / 6$

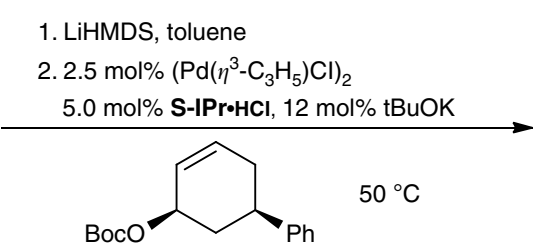

( \pm - 11<smiles>[2H]/C=C\[C@H](c1ccccc1)[C@H](C)C(=O)c1ccccc1</smiles>

$(R, R)-(E)-3 \mathbf{a}$

$(S, S)-(Z)-\mathbf{3 a}$

Attack palladium (inner-sphere mechanism)

$(3 R, 4 \mathrm{~S}, 5 \mathrm{~S})-(E)-31$

$95 \%$ yield, $97 / 3 \mathrm{~B} / \mathrm{L}$

$95 / 5 d r, 92 \%$ ee<smiles>CC(C)[C@H](C(=O)c1ccccc1)C1C=CC[C@@H](c2ccccc2)C1</smiles>

$( \pm)-12$

$73 \%$ yield

Figure 5 | Mechanistic investigations. (a) $(R, R)-(E)$-3a And $(S, S)-(Z)$-3a were afforded by the reaction of $(S)-(Z)-\mathbf{5}$ with ketone 1a, indicating that the reaction proceeds via the inner-sphere mechanism. (b) $(3 R, 4 S, 5 S)-(E)-\mathbf{3 i}$ was the only product in the reaction of $(S)-(Z)-\mathbf{5}$ supports an inner-sphere mechanism. (c) Inversion of the stereocentre at the allyl position of cyclohexene $\mathbf{1 1}$ in the reaction confirms also the inner-sphere mechanism.

Pd-catalysed allylic substitution ${ }^{1-3},(S)-(Z)-3$ and $(R)-(E)-3$ will be formed if the reaction of deuterium-labelled, optically active, allyl ester $(S)-(Z)-\mathbf{5}$ proceeds via an inner-sphere mechanism, while $(R)-(Z)-\mathbf{3}$ and $(S)-(E)-\mathbf{3}$ will be afforded when the outer-sphere mechanism is at work (Fig. 4).

When $(S)-(Z)-5$ was subjected to reaction with ketone 1a (Fig. $5 \mathrm{a})^{33}$, only $(R, \quad R)-(E)-\mathbf{3 a}$ and $(S, S)-(Z)-\mathbf{3 a}$ were obtained after chiral HPLC separation, which clearly suggests that the reaction proceeds via an inner-sphere mechanism. Similarly, the reaction of $(S)-(Z)-5$ with $\beta$-substituted ketones $(S)-\mathbf{1 h}$ yielding $(3 R, 4 S, 5 S)-(E)-\mathbf{3 i}$ (Fig. 5b), also supports that the reaction proceeds via an inner-sphere mechanism. In addition, the fact that the reaction of cis-disubstituted cyclohexene $\mathbf{1 1}$ afforded trans-product 12 in $73 \%$ isolated yield as a single diastereomer (determined by ${ }^{1} \mathrm{H}$ NMR spectroscopy), again, confirms the inner-sphere mechanism (Fig. 5c $)^{7,10}$.

To further understand the reaction mechanism, DFT calculations were carried out on both inner-sphere and outersphere pathways (Fig. 6). The energy reference is set as separated reactants (that is, lithium enolate and allyl-Pd complex). In outersphere pathways, the transition states leading to linear product 


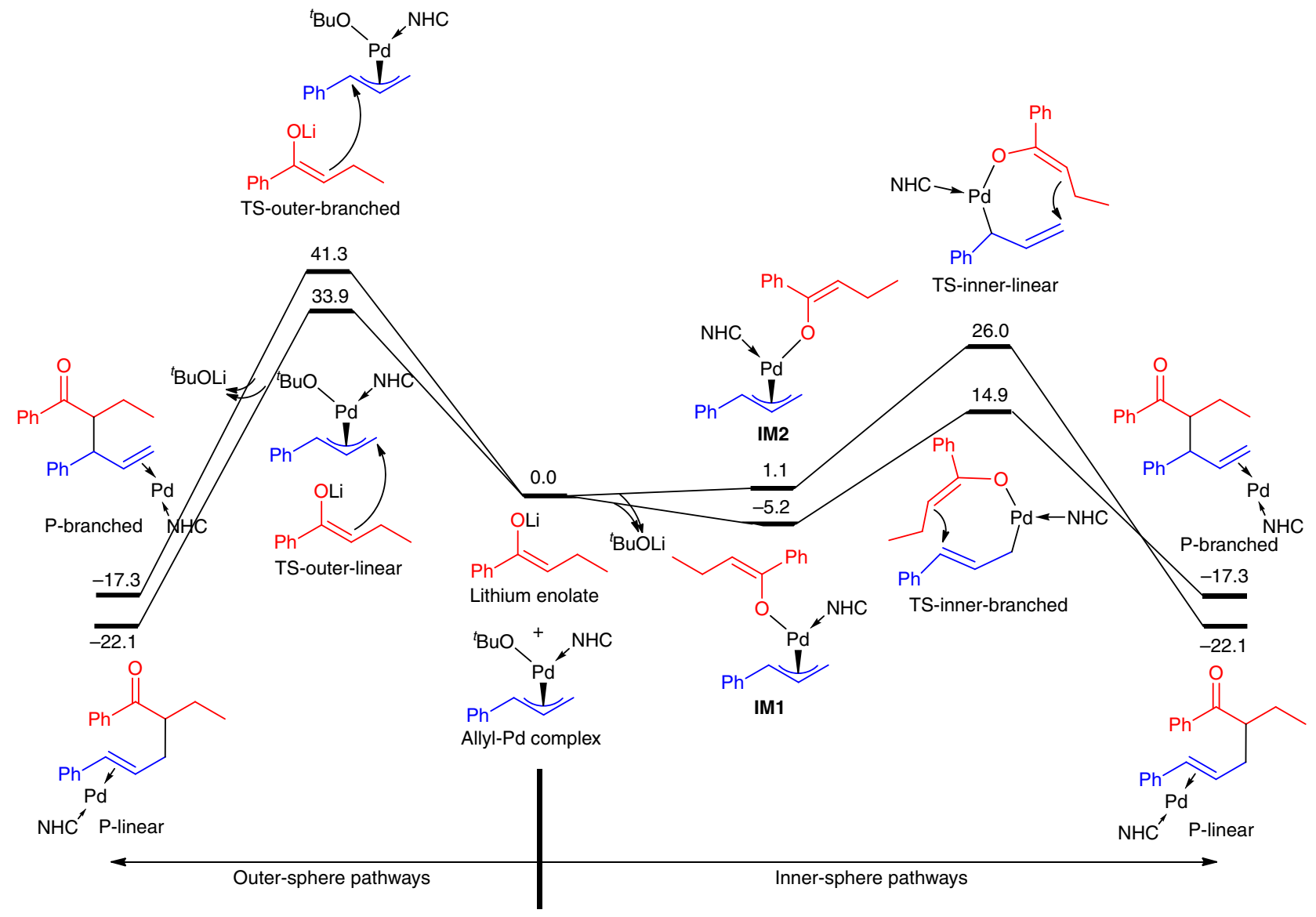

Figure 6 | DFT calculations of the free-energy surface of plausible inner-sphere and outer-sphere pathways of reaction of ketone 1b. Free energies in solvent $\Delta G_{\text {sol }}$ (in $\mathrm{kcal} \mathrm{mol}^{-1}$ ) are computed at $\omega B$ 97XD/def2-TZVP/SMD// $\omega B$ 97XD/SDDAll level of theory. (More detailed calculations on E-enolate and $\eta^{1}$-allyl-Pd intermediates can be found in Supplementary Figures 69 and 71). These calculations suggest that the inner-sphere pathway leading to branched product is the most favourable pathway, in agreement with experiment.

(TS-outer-linear) and branched product (TS-outer-branched) were calculated to be, respectively, 33.9 and $41.3 \mathrm{kcal} \mathrm{mol}^{-1}$ above the separated reactants. These very high-reaction barriers suggest that the outer-sphere mechanism is unlikely to be operative. In addition, if an outer-sphere pathway were followed, linear product would be predicted to be formed exclusively, which contradicts experimental observations. In inner-sphere pathways, lithium enolate first reacts, exothermically, with allyl-Pd complex to yield allyl-Pd enolate (IM1 or IM2) and ${ }^{t} \mathrm{BuOLi}$; then, [3,3'] reductive elimination takes place in the allyl-Pd enolate. The transition state for the branched product (TS-inner-branched) was computed to be $14.9 \mathrm{kcal} \mathrm{mol}^{-1}$ above separated reactants, much lower in energy than TS-inner-linear and the two transition states in outer-sphere pathways. These calculations suggest that the branched product is the kinetically favourable one and should be formed as the major product in experiment through an inner-sphere mechanism. We note here previous theoretical work on the inner- and outer-sphere mechanisms of allylic alkylation of lactones ${ }^{58}$.

To explain the stereochemistry of the reaction, possible conformations of the favourable transition state (TS-innerbranched) of the inner-sphere pathway were explored by DFT calculations (Fig. 7). We find that for the reaction of ketone $\mathbf{1 b}$, the seven-membered ring transition state with a chair conformation is favoured over the boat transition state by $1.4 \mathrm{kcal} \mathrm{mol}^{-1}$. The favourable chair transition state leads to anti product, in agreement with experiment. On the other hand, the boat transition state was predicted to be lower in energy than the chair transition state by $2.0 \mathrm{kcal} \mathrm{mol}^{-1}$ for the reaction of ketone 1c, suggesting that syn product should be the major one. The reversal of diastereoselectivity, predicted by calculations and observed in experiments, on going from reaction of $\mathbf{1 b}$ to $\mathbf{1 c}$, is probably associated with 1,3-diaxial interaction in the chair transition state. The steric encumbrance in the chair transition state for $\mathbf{1 c}$, arising from the phenyl on the allyl and one methyl at the $\beta$ position of the enolate, might destabilize the chair transition state, making it higher in energy than the boat transitions state. However, such, presumably unfavourable, 1,3-diaxial interaction is absent in the chair transition state for $\mathbf{1 b}$.

In summary, a novel, simple and effective Pd/NHC-catalysed protocol has been developed to produce acyclic $\alpha$-allylated ketones bearing three contiguous stereocentres with excellent regio and diastereoselectivities, starting with readily available ketones and allyl reagents. This reaction features facile yet highly efficient Pd catalysis, the use of commercially available NHC ligands and wide substrate scope. It was found that substituents on the NHC and $\beta$-substituents on ketones have a critical impact on the stereochemistry of the reaction. The synthetic applications of the methodology have also been examined preliminarily. The products from current protocol are likely to be useful in the synthesis of more complex molecules. Mechanistic investigations using stereo-probing allyl reagents and DFT calculations suggest that the reaction proceeds via an innersphere mechanism. DFT calculations also showed that the diastereoselectivity of this reaction is highly dependent on the $\beta$-substituent on ketone. 

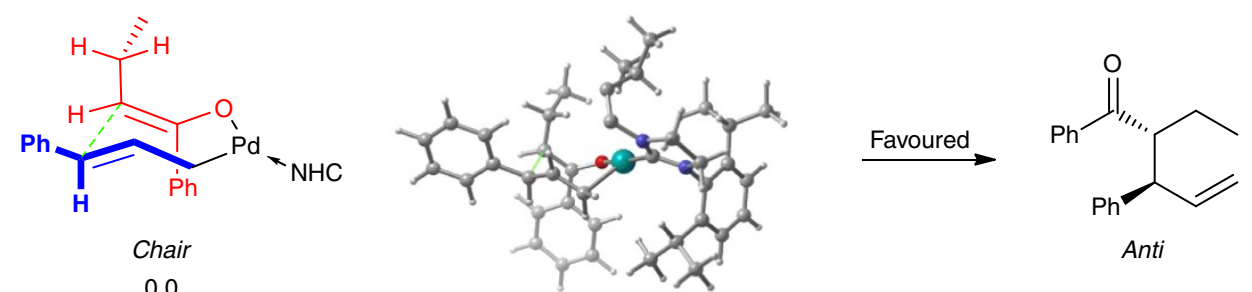

0.0
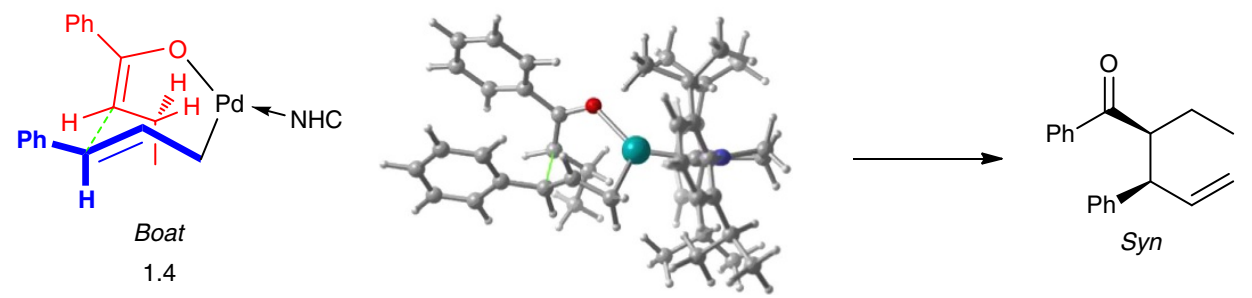

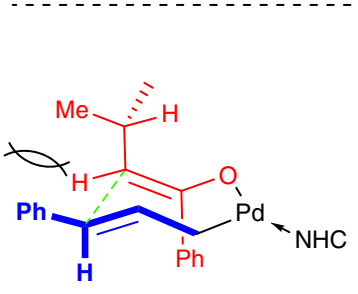

Chair

2.0

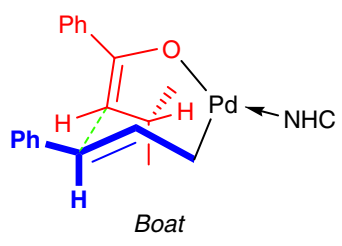

0.0

Substrate 1c
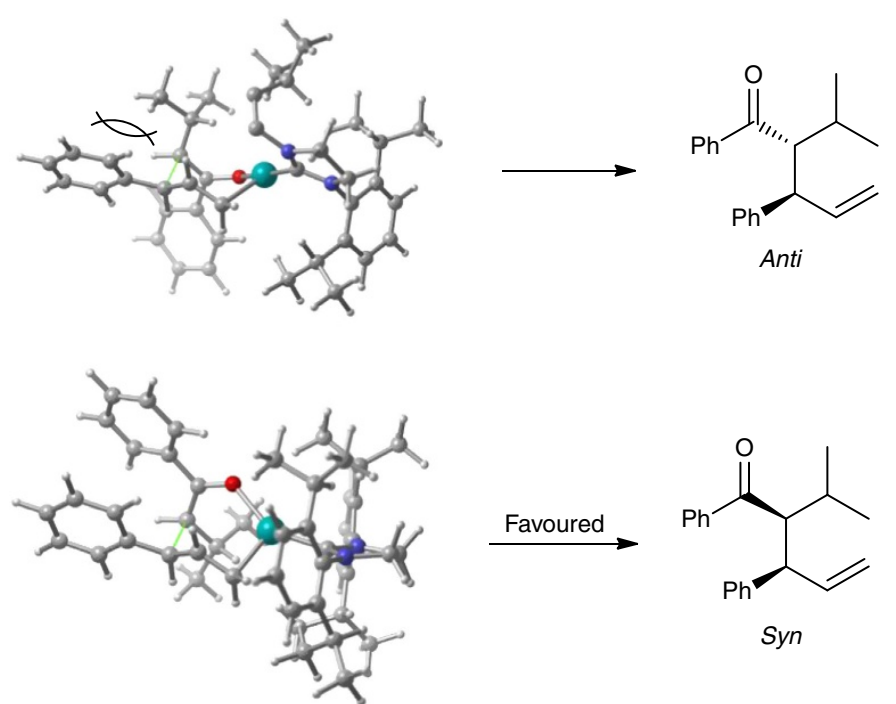

Figure 7 | DFT calculated two major conformations of TS-inner-branched for reactions of ketone $\mathbf{1 b}$ and $\mathbf{1 c}$. For substrate $\mathbf{1 b}$, the chair transition state leading to anti product is favoured, whereas for substrate $\mathbf{1 c}$, the boat transition state leading to syn product is favoured. Detailed analysis and calculations on possible conformations can be found in Supplementary Figures 70-73. Numbers at the bottom of each structure are relative free energies $\Delta \Delta G_{\text {sol }}$ (in

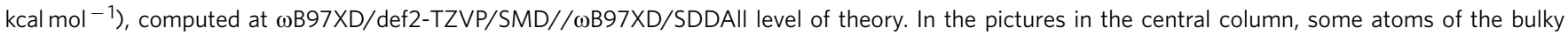
substituents on $\mathrm{NHC}$ are omitted for clarity.

\section{Methods}

Materials. For ${ }^{1} \mathrm{H}$ and ${ }^{13} \mathrm{C}$ NMR spectra of the compounds in this article, see Supplementary Figs 1-66. For X-ray analysis data of 3c, 3f, 7 and 8, see Supplementary Tables 1-4. Details of DFT calculations see Supplementary Figs 67-73 and Supplementary Information Computational methods. For coordinates and energies of calculated structures, see Supplementary Data 1.

General. Commercially available reagents were used without further purification. Solvents were purified before use according to the standard methods. Unless otherwise noted, all reactions were carried out under an atmosphere of argon and flame-dried glassware with standard vacuum-line techniques. NMR spectra are recorded at room temperature on $400 \mathrm{MHz}$ Varian-400, 400M Agilent-400 or $300 \mathrm{MHz}$ Bruker AM-300 NMR spectrometers. The chemical shifts for ${ }^{1} \mathrm{H}$ NMR are reported in p.p.m. from tetramethylsilane with the solvent resonance as the internal standard (7.26 p.p.m. for $\mathrm{CHCl}_{3}$ ). Data are reported as follows: chemical shift, multiplicity $(\mathrm{s}=$ singlet, $\mathrm{d}=$ doublet, $\mathrm{t}=$ triplet, $\mathrm{q}=$ quartet, sept $=$ septet, bs = broad singlet, $\mathrm{m}=$ multiplet), coupling constants $(\mathrm{Hz})$ and integration. Chemical shifts are reported in p.p.m. from tetramethylsilane with the solvent resonance as the internal standard $\left(\mathrm{CDCl}_{3}: 77.15\right.$ p.p.m.). Infra-red spectra were measured in $\mathrm{cm}^{-1}$. HRMS were carried out on the Finnigan MAT 8430 spectrometer. Thin-layer chromatography was performed on pre-coated glassback plates and visualized with ultraviolet light at $254 \mathrm{~nm}$. Flash column chromatography was performed on silica gel.

General procedure for the palladium-catalysed allylic alkylation. A dry Schlenk tube was flame-dried and flushed with Argon. Ketone $1(0.4 \mathrm{mmol})$ and toluene $(2.0 \mathrm{ml})$ were added into the dry Schlenk tube. LiHMDS(1.0 M in THF, $0.4 \mathrm{ml}$, $0.4 \mathrm{mmol}$ ) were added at $0{ }^{\circ} \mathrm{C}$ and stirred at room temperature for $30 \mathrm{~min}$. In a separated flask, $\left[\mathrm{Pd}\left(\eta^{3}-\mathrm{C}_{3} \mathrm{H}_{5}\right) \mathrm{Cl}\right]_{2}(1.9 \mathrm{mg}, 0.005 \mathrm{mmol}), \mathrm{S}-\mathrm{IPr} \cdot \mathrm{HCl}(4.2 \mathrm{mg}$, $0.005 \mathrm{mmol})$ and toluene $(1.0 \mathrm{ml})$ were mixed, followed by addition of $t$-BuOK $(1.0 \mathrm{M}$ in THF, $25 \mu \mathrm{l}, 0.025 \mathrm{mmol})$ at $0{ }^{\circ} \mathrm{C}$. The resulting mixture was stirred at room temperature for $30 \mathrm{~min}$, then added to the ketone solution. The allylic substrate $2(0.2 \mathrm{mmol})$ and toluene $(1.0 \mathrm{ml})$ was then added and the mixture was stirred at corresponding temperature. After the reaction was complete, the reaction mixture was quenched by $\mathrm{H}_{2} \mathrm{O}(0.5 \mathrm{ml})$. The solution was dried (anhydrous $\mathrm{Na}_{2} \mathrm{SO}_{4}$ ) and then filtered through a 0.5 -inch plug of silica gel (eluting with EtOAc) to remove the solid. The crude reaction mixture was concentrated under reduced pressure. $\mathrm{CDCl}_{3}(0.7-0.8 \mathrm{ml})$ was added to dissolve the crude reaction mixture, and mesitylene $(23 \mu \mathrm{l})$ was added as an internal standard. The regio and diastereoselectivity was then determined by ${ }^{1} \mathrm{H}$ NMR spectroscopy. After this analysis, the crude reaction mixture was purified by flash column silica gel chromatography 
(eluting with petroleum ether/toluene $1 / 1$ or petroleum ether/ethyl acetate $10 / 1$ ) to afford the product 3. For additional procedures see Supplementary Methods.

Data availability. The authors declare that the data supporting the findings of this study are available within the article (and Supplementary Information files), and also are available from the corresponding author on request.

\section{References}

1. Trost, B. M. \& Crawley, M. L. Asymmetric transition-metal-catalyzed allylic alkylations: applications in total synthesis. Chem. Rev. 103, 2921-2944 (2003).

2. Lu, Z. \& Ma, S. Metal-catalyzed enantioselective allylation in asymmetric synthesis. Angew. Chem. Int. Ed. 47, 258-297 (2008).

3. Ding, C.-H. \& Hou, X.-L. Transition metal-catalyzed asymmetric allylation. Top Organomet. Chem. 36, 247-285 (2011).

4. Oliver, S. \& Evens, P. A. Transition-metal-catalyzed allylic substitution reactions: stereoselective construction of $\alpha$ - and $\beta$-substituted carbonyl compounds. Synthesis 45, 3179-3198 (2013).

5. You, S.-L., Zhu, X.-Z., Luo, Y.-M., Hou, X.-L. \& Dai, L.-X. Highly regio- and enantioselective Pd-catalyzed allylic alkylation and amination of monosubstituted allylic acetates with novel ferrocene $P, N$-ligands. J. Am. Chem. Soc. 123, 7471-7472 (2001).

6. Weiß, T. D., Helmchen, G. \& Kazmaier, U. Synthesis of amino acid derivatives via enantio- and diastereoselective Pd-catalyzed allylic substitutions with a nonstabilized enolate as nucleophile. Chem. Commun. 12, 1270-1271 (2002).

7. Trost, B. M. \& Thaisrivongs, D. A. Strategy for employing unstabilized nucleophiles in palladium-catalyzed asymmetric allylic alkylations. J. Am. Chem. Soc. 130, 14092-14093 (2008).

8. Zhang, K., Peng, Q., Hou, X.-L. \& Wu, Y.-D. Highly enantioselective Palladium-catalyzed alkylation of acyclic amides. Angew. Chem. Int. Ed. 47, 1741-1744 (2008).

9. Trost, B. M., Xu, J.-Y. \& Schmidt, T. Palladium-catalyzed decarboxylative asymmetric allylic alkylation of enol carbonates. J. Am. Chem. Soc. 131, 18343-18357 (2009).

10. Sha, S.-C., Zhang, J.-D., Carroll, P. J. \& Walsh, P. J. Raising the pKa Limit of "Soft" nucleophiles in Palladium-catalyzed allylic substitutions: application of diarylmethane pronucleophiles. J. Am. Chem. Soc. 135, 17602-1760 (2013).

11. Mukherjee, S. \& List, B. Chiral counter anions in asymmetric transition-metal catalysis: highly enantioselective $\mathrm{Pd} / \mathrm{Br} ø$ nsted acid-catalyzed direct $\alpha$-allylation of aldehydes. J. Am. Chem. Soc. 129, 11336-11337 (2007).

12. Jiang, G.-X. \& List, B. Direct asymmetric $\alpha$-allylation of aldehydes with simple allylic alcohols enabled by the concerted action of three different catalysts. Angew. Chem. Int. Ed. 50, 9471-9474 (2011).

13. Negishi, E. Handbook of Organopalladium Chemistry For Organic Synthesis (Wiley, 2002).

14. Bäckvall, J.-E., Nordberg, R. E., Björkman, E. E. \& Moberg, C. Stereochemistry of nucleophilic attack on $\pi$-allylpalladium complexes. Evidence for cismigration of acetate from palladium to carbon. J. Chem. Soc. Chem. Commun. 943-944 (1980).

15. Hayashi, T., Iwamura, H., Naito, M., Matsumoto, Y. \& Uozumi, Y. Catalytic asymmetric reduction of allylic esters with formic acid catalyzed by Pd-MOP complexes. J. Am. Chem. Soc. 116, 775-776 (1994).

16. Nakamura, H., Bao, M. \& Yamamoto, Y. The Fate of Bis $\left(\eta^{3}\right.$-allyl $)$ palladium complexes in the presence of aldehydes (or imines) and allylic chlorides: stille coupling versus allylation of aldehydes (or imines). Angew. Chem. Int. Ed. 40, 3208-3210 (2001).

17. Stokes, B. J., Opra, S. M. \& Sigman, M. S. Palladium-catalyzed allylic crosscoupling reactions of primary and secondary homoallylic electrophiles. J. Am. Chem. Soc. 134, 11408-11411 (2012).

18. Li, Y.-X. et al. A Pd(0)-catalyzed direct dehydrative coupling of terminal alkynes with allylic alcohols to access 1,4-enynes. J. Am. Chem. Soc. 135, 12536-12539 (2013)

19. Bai, D.-C., Wang, W.-Y., Ding, C.-H. \& Hou, X.-L. Kinetic resolution of unsymmetrical acyclic allyl carbonates using trimethylsilyl cyanide via Palladium-catalyzed asymmetric allylic alkylation. Synlett 26, 1510-1514 (2015).

20. Xiang, S.-H., Hoang, K. L. M., He, J.-X., Tan, Y.-J. \& Liu, X.-W. Reversing the stereoselectivity of a palladium-catalyzed O-Glycosylation through an innersphere or outer-sphere pathway. Angew. Chem. Int. Ed. 54, 604-607 (2015).

21. Méndez, M., Cuerva, J. M., Gómez-Bengoa, E., Cárdenas, D. J. \& Echavarren, A. M. Intramolecular coupling of allyl carboxylates with allylstannanes and allylsilanes: a new type of reductive elimination reaction? Chem. Eur. J. 8, 3620-3628 (2002).

22. Cárdenas, D. J. \& Echavarren, A. M. Mechanistic aspects of C-C bond formation involving allylpalladium complexes: the role of computational studies. New J. Chem. 28, 338-347 (2004).

23. Luzung, M. R., Lewis, C. A. \& Baran, P. S. Direct, chemoselective $\mathrm{N}$-tert -prenylation of indoles by $\mathrm{C}-\mathrm{H}$ functionalization. Angew. Chem. Int. Ed. 48, 7025-7029 (2009).
24. Perez-Rodriguez, M. et al. A DFT study of the effect of the ligands in the reductive elimination from Palladium bis(allyl) complexes. Organometallics 29, 4983-4991 (2010).

25. Keith, J. A. et al. The inner-sphere process in the enantioselective Tsuj allylation reaction with (S)-t-Bu-phosphinooxazoline ligands. J. Am. Chem. Soc 129, 11876-11877 (2007)

26. Enquist, Jr. J. A. \& Stoltz, B. M. The total synthesis of (-)-cyanthiwigin F by means of double catalytic enantioselective alkylation. Nature 453, 1228-1231 (2008).

27. Sherden, N. H., Behenna, D. C., Virgil, S. C. \& Stoltz, B. M. Unusual allylpalladium carboxylate complexes: identification of the resting state of catalytic enantioselective decarboxylative allylic alkylation reactions of ketones. Angew. Chem. Int. Ed. 48, 6840-6843 (2009).

28. Zhang, P., Brozek, L. A. \& Morken, J. P. Pd-catalyzed enantioselective allyl-allyl cross-coupling. J. Am. Chem. Soc. 132, 10686-10688 (2010).

29. Zhang, P., Le, H., Kyne, R. E. \& Morken, J. P. Enantioselective construction of all-carbon quaternary centers by branch-selective Pd-catalyzed allyl-allyl crosscoupling. J. Am. Chem. Soc. 133, 9716-9719 (2011).

30. Brozek, L. A., Ardolino, M. J. \& Morken, J. P. Diastereocontrol in asymmetric allyl-allyl cross-coupling: stereocontrolled reaction of prochiral allylboronates with prochiral allyl chlorides. J. Am. Chem. Soc. 133, 16778-16781 (2011).

31. Ardolino, M. J. \& Morken, J. P. Congested C - C bonds by Pd-catalyzed enantioselective allyl-allyl cross-coupling, a mechanism-guided solution. J. Am. Chem. Soc. 136, 7092-7100 (2014).

32. Ardolino, M. J. \& Morken, J. P. Construction of 1,5-enynes by stereospecific Pd-catalyzed allyl-propargyl cross-couplings. J. Am. Chem. Soc. 134, 8770-8773 (2012).

33. Chen, J.-P., Peng, Q., Lei, B.-L., Hou, X.-L. \& Wu, Y.-D. Chemo- and regioselectivity-tunable $\mathrm{Pd}$-catalyzed allylic alkylation of imines. J. Am. Chem. Soc. 133, 14180-14183 (2011).

34. Keith, J. A. et al. The reaction mechanism of the enantioselective Tsuji allylation: inner-sphere and outer-sphere pathways, internal rearrangements, and asymmetric C - C Bond formation. J. Am. Chem. Soc. 134, 19050-19060 (2012).

35. Nolan, S. P. N-Heterocyclic Carbenes (Wiley-VCH, 2014),

36. Nicolaou, K. C., Vourloumis, D., Winssinger, M. \& Baran, P. S. The art and science of total synthesis at the dawn of the twenty-first century. Angew. Chem. Int. Ed. 39, 44-122 (2000).

37. Gaich, T. \& Baran, P. S. Aiming for the ideal synthesis. J. Org. Chem. 75, 4657-4673 (2010).

38. Newman, D. J. \& Cragg, G. M. Natural products as sources of new drugs over the 30 years from 1981 to 2010. J. Nat. Prod. 75, 311-335 (2012).

39. Wheeler, S. E. Understanding substituent effects in noncovalent interactions involving aromatic rings. Acc. Chem. Res. 46, 1029-1038 (2013).

40. Wheeler, S. E. \& Bloom, J. W. G. Toward a more complete understanding of noncovalent interactions involving aromatic rings. J. Phys. Chem. A. 118, 6133-6147 (2014).

41. Seguin, T. J., Lu, T.-X. \& Wheeler, S. E. Enantioselectivity in catalytic asymmetric fischer indolizations hinges on the competition of $\pi$-stacking and $\mathrm{CH} / \pi$ interactions. Org. Lett. 17, 3066-3069 (2015).

42. Roscales, S., Rincón, Angela., Buxaderas, E. \& Csákÿ, A. G. Trifluoroacetic anhydride-catalyzed conjugate addition of boronic acids to $\alpha, \beta$-unsaturated ketones. Tetrahedron. Lett. 53, 4721-4724 (2012).

43. Chong, J. M., Shen, L. X. \& Taylor, N. J. Asymmetric conjugate addition of alkynylboronates to enones. J. Am. Chem. Soc. 122, 1822-1823 (2000).

44. Krause, N. \& Hoffmann-Roder, A. Recent advances in catalytic enantioselective Michael additions. Synthesis 2, 171-196 (2001).

45. Hayashi, T. \& Yamasaki, K. Rhodium-catalyzed asymmetric 1,4-addition and its related asymmetric reactions. Chem. Rev. 103, 2829-2844 (2003).

46. Tsogoeva, S. B. Recent advances in asymmetric organocatalytic 1,4-conjugate additions. Eur. J. Org. Chem. 11, 1701-1716 (2007).

47. Endo, K., Ogawa, M. \& Shibata, T. Multinuclear catalyst for copper-catalyzed asymmetric conjugate addition of organozinc reagents. Angew. Chem. Int. Ed. 49, 2410-2413 (2010).

48. Nishimura, T., Guo, X.-X., Uchiyama, N., Katoh, T. \& Hayashi, T. Steric tuning of silylacetylenes and chiral phosphine ligands for Rhodium-catalyzed asymmetric conjugate alkynylation of enones. J. Am.Chem. Soc. 130, 1576-1577 (2008).

49. Guo, X. T., Shen, J., Sha, F. \& Wu, X.-Y. Highly enantioselective Michael addition of nitroalkanes to enones and its application in syntheses of (R)-Baclofen and (R)-Phenibut. Synthesis 47, 2063-2072 (2015).

50. Diver, S. T. \& Giessert, A. J. Enyne metathesis (enyne bond reorganization). Chem. Rev. 104, 1317-1382 (2004).

51. Blanco-Urgoiti, J., Añorbe, L., Pérez-Serrano, L., Domínguez, G. \& Pérez-Castells, J. The Pauson-Khand reaction, a powerful synthetic tool for the synthesis of complex molecules. Chem. Soc. Rev. 33, 32-42 (2004). 
52. Mukai, C., Kim, J. S., Sonobe, H. \& Hanaoka, M. Stereocomplementary construction of optically active bicyclo[4.3.0]nonenone derivatives. J. Org. Chem. 64, 6822-6832 (1999).

53. Hiroi, K., Watanabe, T., Kawagishi, R. \& Abe, I. Catalytic use of chiral phosphine ligands in asymmetric Pauson-Khand reactions. Tetrahedron. Asymmetry. 11, 797-808 (2000).

54. Dolhem, F., Lièvre, C. \& Demailly, G. Synthesis of carbohydrate-derived enynes and subsequent metathesis to yield polyhydroxylated 1-vinylcycloalkenes. Eur. J. Org. Chem. 12, 2336-2342 (2003).

55. Funel, J.-A. \& Prunet, J. Enyne versus diene RCM in the synthesis of cyclopentene derivatives toward the A ring of FR182877. J. Org. Chem. 69, 4555-4558 (2004).

56. Xue, Z. J., Chen, P., Peng, S. Y. \& Li, Y. C. Synthesis and determination of absolute configuration of tetracetate 4a-carba-D-xylofuranoside. Tetrahedron 62, 199-204 (2006)

57. Krishna, P. R. \& Alivelu, M. Stereoselective synthesis of aminocyclitol moieties of trehazolin and trehalostatin via enyne metathesis protocol. Tetrahedron Lett. 51, 6265-6267 (2010).

58. Patil, M. \& Thiel, W. Origin of selectivity of Tsuji-Trost allylic alkylation of lactones: highly ordered transition states with lithium-containing enolates. Chem. Eur. J. 18, 10408-10418 (2012).

\section{Acknowledgements}

This paper is dedicated to Professor Henry N. C. Wong on the occasion of his 65th birthday. Financial support by the Major Basic Research Development Program (2011CB808706), NSFC $(21272251,21532010,21421091)$, the NSFC and the RGC Hong Kong Joint Research Scheme (21361162001), the Chinese Academy of Sciences, the Technology Commission of Shanghai Municipality and the Croucher Foundation of Hong Kong is gratefully acknowledged. The computing facilities used in this work at Cornell were supported by EFree (an Energy Frontier Research Center funded by the U.S. Department of Energy (Award No. DESC0001057 at Cornell, subcontract to Carnegie Institution of Washington)). We thank Professor Roald Hoffmann at Cornell University for language revision.

\section{Author contributions}

D.-C.B. initiated the project, designed and completed the experimental works and product characterizations; F.-L.Y., W.-Y.W., H.L., Q.-R.L. did some experiments; D.-C.B. did some analysis of products; C.-H.D. designed some experiments and wrote the manuscript with others; B.C. completed the DFT calculations and wrote the calculation part of the manuscript; X.-L.H. designed and directed the project and wrote the manuscript. All authors joined to discussions.

\section{Additional information}

Accession codes: The X-ray crystallographic coordinates for the structures reported in this article have been deposited at the Cambridge Crystallographic Data Centre (CCDC) under deposition number CCDC 1457162 (for 3c), 1457163 (for 3f), 1457165 (for 7) and 1457166 (for 8). These data can be obtained free of charge from the Cambridge Crystallographic Data Centre via http://www.ccdc.cam.ac.uk/data_request/cif.

Supplementary Information accompanies this paper at http://www.nature.com/ naturecommunications

Competing financial interests: The authors declare no competing financial interests.

Reprints and permission information is available online at http://npg.nature.com/ reprintsandpermissions/

How to cite this article: Bai, D.-C. et al. Palladium/N-heterocyclic carbene catalysed regio and diastereoselective reaction of ketones with allyl reagents via inner-sphere mechanism. Nat. Commun. 7:11806 doi: 10.1038/ncomms11806 (2016).

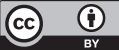

This work is licensed under a Creative Commons Attribution 4.0 International License. The images or other third party material in this article are included in the article's Creative Commons license, unless indicated otherwise in the credit line; if the material is not included under the Creative Commons license, users will need to obtain permission from the license holder to reproduce the material. To view a copy of this license, visit http://creativecommons.org/licenses/by/4.0/ 